J. Nepal Chem. Soc., vol. 29, 2012

\title{
A Study of the Dielectric Constant of Potassium Hexacyanoferrate Trihydrate
}

\author{
S. K. Chakrabarti ${ }^{1^{*}}$, I. S. Jha ${ }^{1}$ and R. N. Yadav ${ }^{2}$ \\ ${ }^{1}$ Dept. of Physics, Tribhuvan University, M. M. A. M. Campus, Biratnagar, Nepal \\ ${ }^{2}$ Dept. of Mathematics, Tribhuvan University, M. M. A. M. Campus, Biratnagar, Nepal \\ E-mail: skc_2007@yahoo.com
}

\begin{abstract}
The variation of dielectric constant with temperature of potassium hexacyanoferrate trihydrate has been reported in this study. It is a monoclinic ferroelectric crystal. As the temperature is gradually increased a jump in the value of its dielectric constant takes place around $57^{\circ} \mathrm{C}$. But as the temperature crosses $145^{\circ} \mathrm{C}$, the dielectric constant increased drastically giving two adjacent peaks at $154^{\circ} \mathrm{C}$ and $157^{\circ} \mathrm{C}$. In course of cooling also the dielectric constant of it shows anomaly-however in diminished order. Such anomalous behaviour of the dielectric constant of potassium hexacyanoferrate trihydrate may be mainly due to its high sensitivity to mechanical stresses, thereby causing piezoelectricity.
\end{abstract}

Keywords: Ferroelectric crystals, Piezoelectricity, Dielectric constant, Advanced materials.

\section{Introduction}

The ferroelectric crystals bear the property that an external electric field can reverse their polarisation. Initially it was only the Rochelle salt which was known to be ferroelectric. Thereafter potassium dihydrogen phosphate and some of its isomorphs were also recognised as ferroelectric substance. Now-a-days it has become a matter of interest to find out new materials having ferroelectric property. Out of thirty-two types of crystal, according to lattice parameters, it is now well known that eleven are non-polar. So, they are not ferroelectric. The remaining crystals do not possess common centre of positive and negative charges within the molecules. They have one or more polar axes and thus ferroelectric in nature. These crystals, except the cubic ones, show piezoelectric effect also i.e. a mechanical stress produces an electric polarisation and reciprocally an applied electric field produces a mechanical strain in them ${ }^{1}$. These ferroelectric materials have several applications of their dielectric properties-linear or nonlinear-and thus emerged as a group of advanced functional materials.

One of the important physical properties of a dielectric is its dielectric constant. As the name itself suggests it generally remains constant for a dielectric. But now it is found that there are several dielectrics whose dielectric constant varies with the physical conditions-regularly or irregularly. If such a dielectric is put inside a capacitor, change in the dielectric constant will give rise to a change in its capacitance also. A change in the capacitance of a capacitor will lead to a change in the reactance of $\mathrm{it}^{2}$. And such change in the capacitative reactance will cause a change in the alternating current through it. In this way these dielectrics have emerged as advanced materials and got wide use in sensors and diverse technological applications.

In the present work we have studied the variation of the dielectric constant of the ferroelectric substance potassium hexacyanoferrate trihydrate with temperature.

\section{* Corresponding author}


J. Nepal Chem. Soc., vol. 29, 2012

\section{Methodology}

Potassium hexacyanoferrate trihydrate is a crystal having chemical formula $\mathrm{C}_{6} \mathrm{FeK}_{4} \mathrm{~N}_{6} \cdot 3 \mathrm{H}_{2} \mathrm{O}$. In the crystalline state it can be obtained with purity more than $99.5 \%$. In a mortar some amount of the crystal was dusted to fine powder. A thin rectangular plate of the dielectric was prepared by heating for few hours below the melting point. Then colloidal silver paint was used at its two broad sides to form a parallel plate capacitor.

The capacitance of the capacitor so formed was measured by a capacitance bridge. For this purpose alternating current was used and the temperature was gradually increased up to $175^{\circ} \mathrm{C}$. The capacitance was measured again in course of cooling also.

\section{Mathematical Approach}

The capacitance $(C)$ of the capacitor was measured by Schering bridge type of capacitance bridge keeping in mind the possibility of dielectric loss ${ }^{3}$.

Using the Wheatstone bridge principle

$$
\frac{P}{Q}=\frac{R}{S}
$$

the capacitative reactance of the capacitor can be found out. But the capacitative reactance is given by ${ }^{4}$

$$
X_{C}=\frac{1}{2 \pi \nu C},
$$

where $v$ is the frequency of the alternating current used. So, knowing the value of $X_{C}$ we have

$$
C=\frac{1}{2 \pi v X_{C}} \text {. }
$$

Now, we recall the expression for the capacitance of a parallel plate capacitor ${ }^{5}$ :

$$
C=\frac{\varepsilon_{0} K A}{d},
$$

where $A$ is the area of each plate of the capacitor, $d$ the distance between them i.e. thickness of the dielectric, $K$ the dielectric constant of it and $\varepsilon_{0}$ the permittivity of free space. Hence, all the terms being known the dielectric constant can be determined by using the formula:

$$
K=\frac{C d}{\varepsilon_{0} A} .
$$

\section{Results}

The dielectric constant of potassium hexacyanoferrate trihydrate is very small. But as the temperature is gradually increased from room temperature the dielectric constant begins to increase after crossing $40^{\circ} \mathrm{C}$ and becomes as high as 158 . Thereafter it falls down gradually and regains its initial value as found at the room temperature. But when we go on increasing the temperature further, the dielectric constant jumps drastically to 1050 and 1312 at $154^{\circ} \mathrm{C}$ and $157^{\circ} \mathrm{C}$ respectively. It is shown graphically in Fig. 1.

In case of cooling from $175^{\circ} \mathrm{C}$ to room temperature the dielectric constant does not retrace its path. The gradual change in the value of $K$ is shown by the cooling curve as furnished in Fig. 2. 


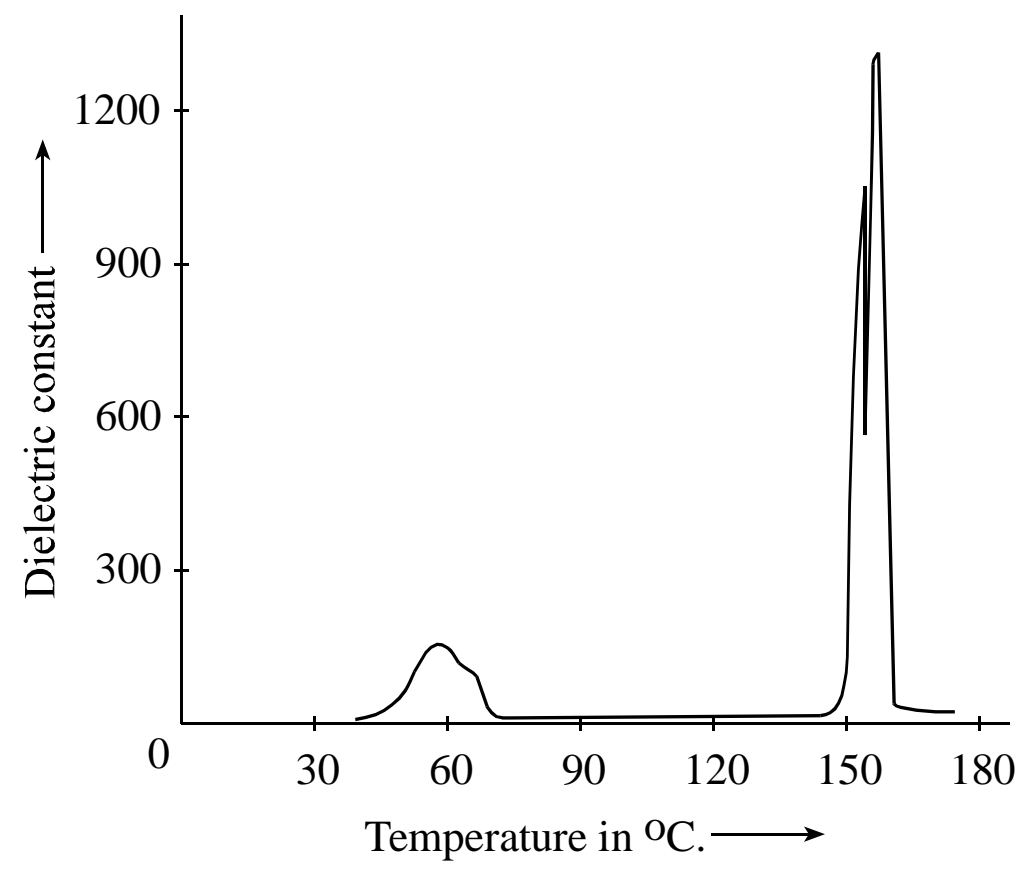

Figure-1: Heating curve

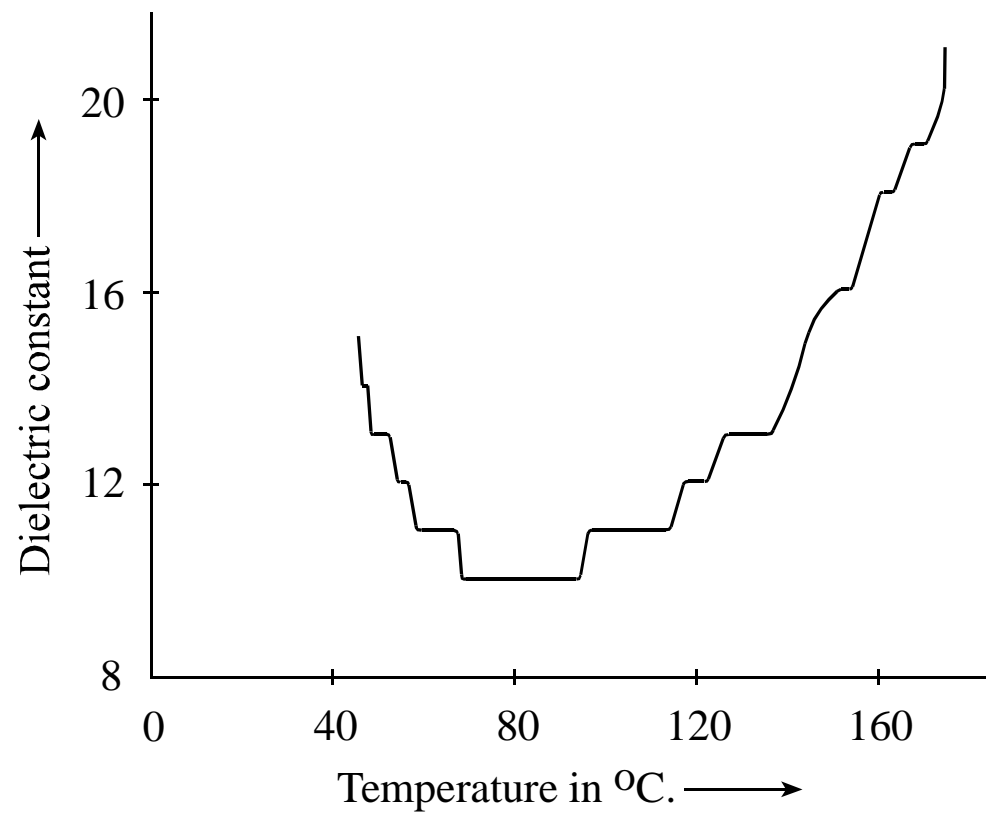

Figure-2: Cooling curve 


\section{Discussion}

Potassium hexacyanoferrate trihydrate is a monoclinic crystal having lattice parameters:

and

$$
\begin{aligned}
& a=9.38 \AA, \\
& b=16.84 \AA, \\
& c=9.40 \AA \\
& \beta=90^{\circ} \pm 3^{\prime}
\end{aligned}
$$

with space group $\mathrm{C} 2 / \mathrm{c}$.

Due to increase in temperature there happens a tetragonal modification with lattice parameters ${ }^{6}$ :

and

$$
\begin{aligned}
& a=9.41 \AA \\
& c=33.67 \AA
\end{aligned}
$$

with space group Cc.

Such change is metastable in nature. So, when the change actually happens and the elementary crystals lose the centre of symmetry, drastic change in the value of dielectric constant takes place.

\section{Conclusion}

The variation in the dielectric constant of potassium hexacyanoferrate trihydrate has been studied with the change of temperature-increasing as well as decreasing. In between the temperatures $150^{\circ} \mathrm{C}$ and $160^{\circ} \mathrm{C}$ spontaneous polarisation occurs within the crystal. That means, the ferroelectric crystal shows piezoelectric effect ${ }^{7}$. The anomaly in the dielectric constant is due to different internal stresses and sensitiveness of the crystal to such mechanical stresses.

\section{Acknowledgement}

The authors would like to thank the Departments of Mathematics and Physics, Tribhuvan University, M. M. A. M. Campus, Biratnagar, Nepal, for providing the available facilities.

\section{References}

1. B. S. Saxena, R. C. Gupta and P. N. Saxena, Solid state physics. Pragati Prakashan, Meerut, 1975

2. C. R. Dasgupta, Physics. Book Syndicate, Kolkata, 1973

3. B. L. Theraja and A. K. Theraja, Electrical technology. S. Chand \& Co., New Delhi, 2005

4. S. K. Gupta and J. M. Pradhan, Physics. Surya Publications, Jalandhar, 2003

5. K. N. Sharma, Modern fundamental physics. Kalyani Publishers, Ludhiana, 1993

6. J. I. Kunrath, C. S. Mullar and E. Frank, J. Therm. Anal. Cal., 2005, 14, 253

7. R. Murugeshan and K. Sivaprasath, Modern physics. S. Chand \& Co., New Delhi, 2005 